\title{
ESTUDO DAS RELAÇÕES DE GÊNERO E REPRESENTAÇÕES SOCIAIS EM UMA ORGANIZAÇÃO HOSPITALAR
}

\author{
OLIVEIRA, André Ribeiro ${ }^{1}$ \\ CRAMER, Luciana ${ }^{2}$ \\ GAIO, Luiz Eduardo ${ }^{3}$ \\ BONACIM, Carlos Alberto Grespan ${ }^{4}$
}

Recebido em: 2009-02-26

Aprovado em: 2009-09-10

ISSUE DOI: $10.3738 / 1982.2278 .173$

RESUMO: As organizações hospitalares vêm passando por mudanças e, para se manterem num mercado cada vez mais competitivo, devem adaptar-se ao contexto no qual estão inseridas, direcionando suas ações rumo a uma maior flexibilidade. Uma das conseqüências dessa busca é a diversificação da mão-de-obra, resultando em uma força de trabalho cada vez mais heterogênea. Dessa forma, uma importante dimensão a ser estudada é a crescente participação da mulher neste mercado de trabalho. Por meio deste artigo, buscou-se compreender a natureza da diversidade organizacional socialmente construída em torno das relações de gênero presentes em uma organização hospitalar no sul de Minas Gerais. Para tanto, buscou-se interpretar as Representações Sociais elaboradas por médicos,e enfermeiros em torno das relações de gênero na organização estudada. Constatou-se que a representação de profissões tipicamente masculinas ou femininas ainda persiste nas relações de trabalho entre as classes profissionais pesquisadas, mesmo estando em igualdade de condições em termos de formação especifica, cultura e competência.

Palavras-chave: Relações de gênero. Representações Sociais. Organizações hospitalares.

\section{STUDY OF GENDER RELATIONS AND SOCIAL REPRESENTATIONS IN A HOSPITAL}

SUMMARY: Hospitals are facing changes and, to survive in such a competitive market, they must adapt to the context in which they are inserted, directing their actions towards a greater flexibility. A consequence of this move is the workforce diversification. Thus, the increasing women's participation in this area is an important dimension to be studied. This paper aimed to comprehend the nature of the organizational diversity socially built about the gender relations present in a hospital located in the southern part of Minas Gerais. It sought to interpret the social representations elaborated by physicians and nurses about gender relations in this organization. It was verified that the representation of typically male or female occupations still persists in the work relations between the professionals researched, even having the same conditions concerning specific formation, culture and competency.

Keywords: Gender relations. Social representations. Hospitals.

\footnotetext{
${ }^{1}$ Mestrando em Administração pela Universidade Federal de Lavras. Administrador Júnior da Petrobrás.

${ }^{2}$ Doutora em Administração pela Universidade Federal de Lavras. Professora do Unilavras

${ }^{3}$ Mestrando em Administração de Organizações pela Faculdade de Economia, Administração e Contabilidade de Ribeirão Preto da Universidade de São Paulo (FEA-RP/USP). Professor da FE/FFCL - Ituverava.

${ }^{4}$ Doutorando em Contabilidade pela Faculdade de Economia, Administração e Contabilidade da Universidade de São Paulo (FEA/USP).
} 


\section{INTRODUÇÃO}

As mudanças ocorridas nas últimas décadas, tais como o processo de globalização, os avanços tecnológicos, a introdução de novos modelos de gestão, dentre outras, modificaram o cotidiano das pessoas e das organizações e estabeleceram uma nova forma de relacionamento entre os seres humanos. O cenário atual de constantes transformações ambientais impõe às organizações uma nova dinâmica, o que resulta em uma busca por adequação a essa nova condição e por obtenção de competitividade em produtos, serviços e processos.

Como não poderia ser diferente, as organizações hospitalares também vêm passando por mudanças e, para se manterem num mercado cada vez mais competitivo, essas organizações devem buscar adaptar-se ao contexto no qual estão inseridas, direcionando suas ações rumo a uma maior flexibilidade. Uma das conseqüências dessa busca é a diversificação da mão-de-obra, resultando em uma força de trabalho cada vez mais heterogênea.

Dentre a diversidade cultural presente nas organizações, existe uma dimensão importante a ser estudada, que é a crescente participação da mulher no contexto do trabalho. De acordo com o Instituto Brasileiro de Geografia e Estatística (IBGE), citado por Uchinaka (2004), as mulheres representam quase metade da População Economicamente Ativa (PEA) do país e, desse total, $38 \%$ encontram-se empregadas.

Todas estas questões modificaram as relações de trabalho e despertaram o interesse de pesquisadores, gerando assim debates tanto no meio acadêmico como em toda a esfera socioeconômica, sendo que o tema tem sido abordado sob diversos pontos de vista e caminhos teórico-metodológicos.

Nesse trabalho, buscar-se-á compreender a natureza da diversidade organizacional socialmente construída em torno das relações gênero presentes em uma organização hospitalar do sul de Minas Gerais. Esse artigo enfoca o problema valendo-se da noção de identidade de gênero, mais particularmente, do que se constrói e desconstrói como identidade masculina e feminina no âmbito do trabalho. Para tanto, buscar-se-á interpretar as Representações Sociais elaboradas por médicos e enfermeiros ${ }^{5}$ em torno das relações de gênero na organização estudada.

$\mathrm{O}$ presente estudo é parte integrante de um projeto financiado pela $\mathrm{CNPq}$ (Conselho Nacional de Desenvolvimento Científico e Tecnológico) intitulado "Representações Sociais das Relações de Gênero em Organizações Hospitalares” e que tem por objetivo investigar as

\footnotetext{
${ }^{5}$ Quando o artigo refere-se a enfermeiros e enfermeiras, está se referindo, na verdade, à classe de profissionais da área de enfermagem, que abrange: enfermeiros (as) padrão, técnicos(as) de enfermagem e auxiliares de enfermagem. Optou-se pela denominação enfermeiros (as) para efeito de simplificação de redação.

Nucleus, v.6, n.2, out. 2009
} 
Representações Sociais construídas em torno das relações de gênero em organizações hospitalares.

\section{REFERENCIAL TEÓRICO}

\subsection{RELAÇÕES DE GÊNERO}

Nas últimas décadas ocorreu um desenvolvimento da pesquisa sobre relações de gênero, um tema antes considerado simples e sem ambigüidades, e hoje enxergado como algo altamente complexo, dinâmico e ambíguo (CALAS; SMIRCICH, 1999; HARDING, 1987).

Este desenvolvimento é em parte associado ao surgimento do pós-modernismo/pósestruturalismo (NICHOLSON, 1990). Conceitos como homens e mulheres, masculino e feminino, são vistos cada vez mais como ambíguos e mutáveis. Gênero é visto por muitos pesquisadores como uma construção social e lingüística, como um significado instável atribuído ao masculino e ao feminino.

O termo gênero, segundo Scott (1995, p.72) "parece ter feito sua aparição inicial entre as feministas americanas, que queriam enfatizar o caráter fundamentalmente social das distinções baseadas no sexo". Thomas Laquer apud Sabat (1999), afirma que foi no século XVIII que se passou a definir mulher e homem como seres diferentes. A íntima relação entre biologia e sexualidade permaneceu não questionada por muito tempo, para em seguida ser trazida à tona, através do argumento de que é, principalmente, no corpo que se inscrevem as marcas da cultura, as distinções sociais, raciais e de gênero, e é através delas que se identificam marcas de igualdades e de diferenças. (SABAT, 1999).

O lugar social das mulheres sempre foi determinado em oposição ao lugar social dos homens. Força, autoridade e virilidade foram estabelecidas como símbolos culturais dominantes em oposição à fragilidade, à fraqueza, à sensibilidade, características consideradas femininas. A partir desses binarismos, criaram-se códigos sociais e legislações, estabeleceram-se regimes políticos, formaram-se sistemas de significados que, de modo não intencional, contribuíram para legitimar relações desiguais entre os sexos. (SABAT, 1999).

Para Louro (2000), gênero se caracteriza como uma construção social feita sobre as diferenças sociais. Trata-se, portanto, do modo como essas diferenças sexuais são compreendidas numa dada sociedade, num grupo, em um contexto determinado por um processo histórico. 
O termo 'gênero' está ganhando popularidade. O seu significado era assumido como relativamente claro; ele era usado para se referir aos papéis e expectativas sociais atribuídas ou vividas por pessoas em relação ao seu sexo biológico. Mas gênero está transformando-se em um conjunto de significados mais amplo e difuso. Gênero tem se tornado um rótulo geral para se falar sobre mulheres, homens, seus relacionamentos, aspectos relacionados à organização, processos através dos quais padrões de comportamento diferenciado em relação ao gênero são representados, e tópicos de poder sob várias óticas. Incorpora, inclusive, atenção aos interesses dos homens, embora a ênfase das pesquisas ainda seja as mulheres. $\mathrm{O}$ amplo domínio de tópicos rotulados de 'gênero' é, sem dúvida, potencialmente confuso (LEONARD, 2002).

Mas o que é definido como sendo masculino ou feminino em situações diversas? O que tais definições significam em conexão com o funcionamento e gerenciamento da força de trabalho nas organizações? Como os discursos e as relações de gênero influenciam as organizações e como as organizações constroem o gênero? Talvez o aspecto mais importante é que respostas definidas e finais não são possíveis. Teorias locais, historicamente conscientes, são enfatizadas em detrimento de teorias universais. A diversidade é enfatizada. Classe social, raça, orientação sexual, idade, situação familiar, condições nacionais e regionais, estilo de vida e interesses pessoais podem ser vistos como fontes vitais de diferenciação (CHAFETZ, 1989). Algumas vezes os conceitos universais como homens, mulheres, masculino, feminino, identidade de gênero, e reprodução, são problematizados porque eles tendem a indicar uma falsa unidade (ALVESSON, 1998).

A partir do momento em que as mulheres começaram a se inserir no mercado de trabalho, as questões que envolvem as relações de trabalho entre a mão-de-obra masculina e feminina começaram a emergir. Os discursos organizacionais sempre pregaram igualdade de condições e oportunidades para o sexo feminino e masculino no ambiente organizacional, entretanto ainda existe uma clara evidência com relação à desigualdade da participação da mulher no mercado de trabalho. Seja quanto aos níveis salariais, possibilidade de crescimento na carreira ou oportunidades de exercer determinadas funções, o trabalho da mulher ainda sofre limitações.

Enquanto a desigualdade de gênero ainda persiste em diferentes níveis organizacionais, sua natureza oculta a previne de ser percebida como tal. Um conjunto de processos escondidos, baseados em relações de poder ou acordos que sistematicamente (re)produzem distinções de gênero explica tanto as práticas persistentes da desigualdade quanto a percepção dominante da igualdade de gênero. A representação neutra de gênero

Nucleus, v.6, n.2, out. 2009 
esconde os efeitos de gênero e os molda como práticas sociais normais, inerentes à rotina organizacional (BENSCHOP; DOOREWARD, 1998).

A visão de que a organização é um espaço público, hierárquico e 'mapeável', naturalmente ocupado pelos homens, tornou-se um fundamento da teoria e prática organizacional tradicional (ACKER; VAN HOUTEN, 1991; BURREL; HEARN, 1989; HEARN; PARKIN, 1983; MILLS; TANCRED, 1992). As mulheres foram amplamente ignoradas como um aspecto reconhecível de estudo. Quando o tema gênero começou a aparecer nos escritos organizacionais, a metáfora de espaço permaneceu como um modelo dominante de significado na qual não somente as organizações, mas também o gênero passou a ser conceituado.

Benschop; Dooreward (1998) argumentam que as práticas de gênero estão inscritas no dia-a-dia organizacional, e que para quebrar a evidência desses processos, as 'mulheres bem sucedidas' ficam sob os holofotes. Isso pode gerar algum conforto, mas não mais do que isso, enquanto tira a atenção das desigualdades sistemáticas de gênero. É importante que a existência de distinções seja reconhecida, ao invés de normas e valores correntes de igualdade, e que se reconheça que essas distinções são significativas para a prática organizacional, porque elas facilitam a (re) produção da desigualdade de gênero.

\subsection{REPRESENTAÇÕES SOCIAIS}

O objetivo das Representações Sociais é estudar os atores sociais em movimento, suas idéias e concepções de mundo que estão representadas (por isso 'representação social') nas suas falas. Essas representações não são necessariamente conscientes, sendo uma mistura das idéias das elites, das grandes massas e das filosofias correntes, contendo elementos de dominação e de resistência; cabe ao pesquisador revelar a contradição das Representações Sociais que podem ser pesquisadas por diversos campos de conhecimento, tais como antropologia, história da cultura, sociologia e psicologia Social.

A partir do termo "senso comum", Shultz apud Minayo (ibid., p.164) aborda as Representações Sociais, considerando que a existência cotidiana "é dotada de significados e portadora de estruturas de relevância para os grupos sociais que vivem, pensam e agem em determinado contexto social". Tais significados são selecionados através de construções mentais, de "representações do 'senso comum', estruturas significativas da cotidianidade que resultam de um estoque de experiências pessoais e de outros, isto é, de companheiros, predecessores, contemporâneos, consociados e sucessores". Por meio do senso comum, o ator 
social age e atribui significados portadores de relevância à sua ação, "de acordo com sua história de vida, seu estoque de conhecimentos formados pela tipificação deste mesmo senso comum".

Representação social, segundo Minayo (1996), é um termo filosófico que significa a reprodução de uma percepção retida na lembrança ou do conteúdo do pensamento. Ele acrescenta que nas ciências sociais elas são definidas como categorias de pensamento que expressam a realidade, explicando-a, justificando-a ou questionando-a.

Para Guareschi; Jovchelovitch (1994), a Teoria das Representações Sociais se coloca contra a Psicologia Social no modo de ver o indivíduo, uma vez que a teoria das Representações Sociais vê tanto o sujeito como o objeto, recuperando desta forma um sujeito que, através de sua atividade e relação com o objeto mundo, constrói tanto o mundo como a si próprio. Os autores acrescentam que a teoria de Moscovici estabelece uma síntese teórica entre fenômenos que, ao nível da realidade, estão profundamente ligados. A dimensão cognitiva, afetiva e social estão presentes na própria noção de representação social.O papel da Teoria das Representações Sociais é conferir racionalidade à crença coletiva e sua significação, portanto, às ideologias, aos saberes populares e ao senso comum (MOSCOVICI,1976).

Lane (1986) ressalta que as Representações Sociais se estruturam tanto pelos objetivos da ação do sujeito social, quanto pelos dados que concordam ou que se opõem a eles, é por meio da relação com os outros que a representação social é elaborada, sendo portanto essencial nesse processo a linguagem, pois é através dela que se descreve, explica-se e acredita-se na realidade, o que é feito de acordo com o grupo social do qual se faz parte.

Silva (1998) diz que as Representações Sociais, enquanto formas de conhecimento prático orientado para a compreensão do mundo e para a comunicação, são estruturas cognitivas, sociais e afetivas. Por isso, elas não podem ser reduzidas apenas ao seu conteúdo cognitivo; precisam ser entendidas a partir do contexto em que se encontram e a partir de sua funcionalidade nas interações sociais do cotidiano. O autor acima continua dizendo que as Representações Sociais se manifestam em palavras, sentimentos e condutas, e se institucionalizam. Portanto, podem e devem ser analisadas a partir da compreensão das estruturas e dos comportamentos sociais, sendo que sua mediação privilegiada é a linguagem, tomada como forma de conhecimento e de interação social.

As representações não são percebidas em nível individual, pois é a sociedade que pensa. Portanto, as Representações Sociais são construídas socialmente. O indivíduo tem um

Nucleus, v.6, n.2, out. 2009 
papel ativo na construção da sociedade, ao mesmo tempo em que é criado por ela. As Representações Sociais tratam do processo de diferenciação social, de percepção do outro.

Pode-se afirmar que o que é importante é a natureza da mudança através da qual as Representações Sociais se tornam capazes de influenciar o comportamento do indivíduo participante de uma coletividade. É dessa maneira que elas são criadas, internamente, mentalmente, pois é dessa maneira que o próprio processo coletivo penetra, como o fator determinante, dentro do pensamento individual.

De acordo com Moscovici (1976), pessoas e grupos criam representações no decurso da comunicação e da cooperação. Representações, obviamente, não são criadas por um indivíduo isoladamente. Uma vez criadas, contudo, elas criam uma vida própria, circulam, se encontram, se atraem e se repelem, e dão oportunidade ao nascimento de novas representações, enquanto que velhas representações morrem. Como conseqüência disso, para se compreender e explicar uma representação, é necessário começar com aquela, ou aquelas, das quais ela nasceu. Não é suficiente começar diretamente de tal ou tal aspecto, seja do comportamento, seja da estrutura social. Uma representação muitas vezes condiciona ou até mesmo responde a elas.

Isso é assim, não porque ela possui uma origem coletiva, ou porque ela se refere a um objeto coletivo, mas porque, como tal, sendo compartilhada por todos e reforçada pela tradição, ela constitui uma realidade social sui generis. Quanto mais sua origem é esquecida, e sua natureza convencional ignorada, mais fossilizada ela se torna. O que é ideal, gradualmente tornase materializado. Cessa de ser efêmero, mutável e mortal, e torna-se, em vez disso, duradouro, permanente, quase imortal.

A motivação para a elaboração de Representações Sociais não é, pois, uma procura por um acordo entre nossas idéias e a realidade de uma ordem introduzida no caos do fenômeno ou, para simplificar, um mundo complexo, mas a tentativa de construir uma ponte entre o estranho e o familiar; e isso na medida em que o estranho pressuponha uma falta de comunicação dentro do grupo, em relação ao mundo, que produz um curto-circuito na corrente de intercâmbios e tira do lugar as referências da linguagem. Tem-se a sensação de que ele não se ajusta mais à matriz da vida em comum, que não mais concorda com nossas relações com os outros. Para controlar uma idéia ou percepção estranhas, começa-se por ancorá-lo em Representações Sociais existentes e é no curso dessa ancoragem que ele se modifica (MOSCOVICI, 1976).

Para levar mais adiante a explicação da formação dessas representações, torna-se necessário esclarecer algumas dificuldades. A procura pelo familiar em uma situação estranha significa que essas representações tendem para o conservadorismo, para a confirmação de seu 
conteúdo significativo. Bem, isso seria, então, a pura e simples conseqüência de seu sociocentrismo, do caráter sociomórfico de suas operações cognitivas e lingüísticas. Isso significa que existe certa distância em relação à realidade não representada pelo grupo.

Mas seria essa uma questão de uma característica peculiar a representações nãocientíficas e não-racionais, como afirmam alguns? A observação nos mostra que as representações científicas são também centradas, embora de maneira diferente, na comunidade científica e na sociedade da qual ela é uma parte. Poderia acrescentar que os paradigmas de uma ciência normal demonstram igualmente uma tendência ao conservadorismo em face de anomalias, até ao ponto em que sua resistência se torna impossível (KUHN, 1962).

Do ponto de vista dinâmico, as Representações Sociais se apresentam como uma 'rede' de idéias, metáforas e imagens, mais ou menos livremente interligadas e, por isso, mais móveis e fluidas que teorias.

Parece que existe uma 'enciclopédia' de tais idéias, metáforas e imagens que são interligadas entre si de acordo com a necessidade dos núcleos, das crenças centrais (ABRIC, 1989) armazenadas separadamente em nossa memória coletiva e ao redor das quais essas redes se formam.

\subsection{ORGANIZAÇÕES HOSPITALARES}

A palavra hospital é derivada do latim hospitium, que significa convidado, hóspede. Acredita-se que a assistência hospitalar teve início na China, no século XII a.C., onde havia agências para o atendimento de doentes pobres (RAMOS, 1972). Na Grécia, os "asclépios" eram templos que recebiam doentes, geralmente viajantes e, provavelmente, influenciaram as observações de Hipócrates, considerado o pai da medicina empírica. Em Roma, os hospitais eram predominantemente militares, voltados à recuperação dos soldados para novas lutas (SALES, 1971).

O hospital, como instrumento terapêutico, é uma invenção do final do século XVIII. Com a necessidade de se evitar a morte de muitos soldados treinados, além de outras razões de ordem econômica e do receio da proliferação de epidemias, o hospital passou por uma transformação, tornando-se mais organizado, a missão evoluiu para além da cura, buscando a prevenção de doenças e a manutenção da saúde (SALES, 1971).

Atualmente, o hospital é visto como um negócio que precisa se adequar aos moldes da administração empresarial, até mesmo por uma questão de sobrevivência, pois o mercado vem

Nucleus, v.6, n.2, out. 2009 
se tornando cada vez mais competitivo. Nesse contexto, as organizações de saúde e os seus respectivos colaboradores precisam desenvolver uma dinâmica de aprendizagem e inovação, cujo primeiro passo deve ser a capacidade crescente de adaptação às mudanças observadas no mundo contemporâneo. É preciso aprender as habilidades e os conhecimentos necessários e a melhor maneira de transmiti-los para formar esses novos profissionais, adaptados à realidade atual e preparados para acompanhar as transformações futuras.

Assim, apresenta-se como fundamental para a sobrevivência dos hospitais a busca por maior modernização gerencial, para realizar a reestruturação interna necessária, no sentido de otimizar os processos e gerenciar os custos, como também para se estruturar melhor na discussão com outros setores e atores inter-relacionados.

\subsection{SOCIOLOGIA DAS PROFISSÕES (MEDICINA/ENFERMAGEM)}

\subsubsection{MEDICINA}

Ser médico não é tarefa fácil, pois se exige muito do indivíduo, não importando o tempo e as circunstâncias sociais envolvidas. Espera-se daquele que exerce o ofício de médico um porte social diferenciado. No princípio, os médicos eram tidos e aceitos como intermediários entre os homens e os deuses, o que originou parte do conceito de ser a Medicina um sacerdócio, hoje lhes é cobrado um conhecimento científico infinito que vence todas as doenças e afasta o inevitável e derradeiro confronto da humanidade individual: a morte; e tudo isso em apenas um único ser humano (ANDRADE, 2004).

Para Andrade (2004), o médico possui privilégios especiais, como ter acesso pleno ao corpo das pessoas, ter conhecimento dos seus mais íntimos segredos pessoais e poder interferir em suas vidas a ponto de modificá-las em sua totalidade. Mas a detenção de tamanhos privilégios resulta em iguais responsabilidades sociais. Desta forma, a medicina não pode ser exercida por qualquer um, "tem que ser alguém especial, não melhor ou maior que os outros, mas magnificamente especial” (ANDRADE, 2004, p. 01).

A fonte do poder e do grande prestígio social usufruído pelo profissional de medicina passou a ser localizada, não só na importância do saber que ele domina e controla, como também no contexto social mais amplo ao nível do Estado que, por vários motivos, principalmente de autopreservação, tem interesse na manutenção e difusão desse tipo de instituição. 
Para Friedson (1970), uma profissão distingue-se em relação a outras ocupações menores no que se refere à autonomia organizada e legitimada em seu poder. Tal autonomia confere à profissão um monopólio ocupacional que assegura uma posição de dominância no interior do processo de divisão de trabalho.

\subsubsection{ENFERMAGEM}

Antigamente, a enfermagem era constituída por elementos como solidariedade humana, misticismo, senso comum e crendices. Mas hoje, devido ao desenvolvimento da ciência, em todas as suas áreas, a profissão de enfermeiro passou a se respaldar em aspectos científicos, tecnológicos e humanísticos, sendo que a atividade de cuidar da saúde representa o cerne de suas responsabilidades. A enfermagem passou a ser uma ciência com campo de conhecimento específico.

Carvalho; Castro (1979) colocam que o profissional de enfermagem surgiu no Brasil para atender as necessidades da saúde pública. Uma característica muito forte ligada à imagem do enfermeiro é a "doença" ou o "ambiente hospitalar", talvez porque o profissional atua, principalmente, na área curativa. Gastaldo; Meyer (1989) afirmam que a enfermagem profissional já nasce vinculada ao hospital, o que talvez justifique seu enfoque predominantemente curativo, que persiste até os dias de hoje.

No Brasil, a enfermagem é exercida por três categorias profissionais: o enfermeiro com formação superior, o técnico e o auxiliar de enfermagem de nível médio. Parece que o enfermeiro para a população, quando mencionado como aquele que está "próximo ao paciente", pode ser o técnico ou o auxiliar, não havendo distinção entre as diferentes categorias profissionais dentro da enfermagem. A proximidade técnica das ações destes profissionais favorece tal percepção e ainda o fato de muitos procedimentos serem executados por um ou por outro, contribui para a não distinção entre as profissões.

De acordo com Gamanikow citado por Meyer (1993, p.48),

[...]a enfermagem é um trabalho de mulheres, uma vez que estas estão peculiarmente adaptadas para a onerosa tarefa de cuidar hábil e pacientemente do doente, obedecendo fielmente ordens médicas. A habilidade para cuidar do doente é uma natureza distintiva da mulher. Enfermagem é servir de mãe a pessoas adultas quando muitos doentes são como crianças.

A falta de reconhecimento do profissional de enfermagem por outros profissionais, especialmente da área de saúde, é visto por Arduini (1964) como resultado do fato da enfermeira estar cercada pelo estereótipo da feminilidade, que não dá lugar para a liderança e

Nucleus, v.6, n.2, out. 2009 
ambição. Isso a leva em direção à acomodação, temendo ser mal vista ao usar padrões de comportamento que para muitos são específicos dos homens.

Para Silva (1986), as enfermeiras que freqüentemente possuem a mesma origem de classe social dos médicos e um nível de escolaridade semelhante, encontram-se numa posição subordinada em relação a eles. Dentre alguns aspectos que podem explicar esta situação, estão: o retardamento do processo de profissionalização e do processo de cientifização da enfermagem e também o fato de ser uma categoria dominantemente feminina.

Epsten citado por Silva (1979) também se refere às dificuldades de postura do enfermeiro, tendo como origem direta a posição da mulher na sociedade, onde sempre foi considerada intelectualmente inferior ao homem; essa atitude é constatada na relação médicoenfermeira.

\title{
3 METODOLOGIA
}

O presente trabalho, de caráter qualitativo, utilizou o estudo de caso para a investigação de uma unidade de pesquisa (uma organização hospitalar). Foram empregadas entrevistas semi-estruturadas em profundidade para a coleta de dados, e utilizou-se a análise de conteúdo para a interpretação dessas entrevistas.

\subsection{ANÁLISE DE CONTEÚDO}

A análise de conteúdo tem sido muito utilizada na análise de comunicações nas ciências humanas e sociais. Para Bardin (1979), a análise de conteúdo constitui:

\begin{abstract}
Um conjunto de técnicas de análise de comunicação visando a obter, por procedimentos sistemáticos e objetivos de descrição do conteúdo das mensagens, indicadores (quantitativos ou não) que permitam a inferência de conhecimentos relativos às condições de produção/recepção destas mensagens. (BARDIN, 1979).
\end{abstract}

Esse tipo de análise visa, portanto, "a ultrapassar o nível do senso comum e do subjetivismo na interpretação e alcançar uma vigilância crítica em relação à comunicação de documentos, textos literários, biografias, entrevistas ou observação” (MINAYO, 1996).

\subsection{ENTREVISTA SEMI-ESTRUTURADA EM PROFUNDIDADE}

Sá (1998) comenta que a técnica de entrevista em profundidade deve ser iniciada com perguntas de caráter mais concreto, fatuais e relacionadas às experiências cotidianas dos

Nucleus, v.6, n.2, out. 2009 
sujeitos, para "gradativamente passar a perguntas que envolvam reflexões mais abstratas e julgamentos".

Assim, busca-se realizar um aprofundamento, que segundo o autor ocorre em três fases: pré-análise; exploração do material e tratamento dos resultados. A pré-análise é a fase da organização, aquela com o objetivo de sistematizar as idéias iniciais. Embora compreenda um "período de intuições", conduz a um plano de análise com um esquema preciso do desenvolvimento das fases. A segunda fase consiste em categorizar os dados. Por fim, o tratamento dos resultados é a fase em que se buscam conclusões, inferências a respeito do tema estudado.

\subsection{ESTUDO DE CASO}

O método de estudo de caso, especialmente adequado para quando o pesquisador está interessado na relação entre o contexto e o fenômeno de interesse, surge como ferramenta apropriada para pesquisas. Fundamentalmente, os estudos de caso são sugeridos quando (BENBASAT et al., 1987):

a) os fenômenos são examinados em seu ambiente natural,

b) coletam-se os dados por múltiplos meios,

c) uma ou algumas unidades são foco de análise,

d) a complexidade de cada uma é estudada profundamente,

e) contemplam-se a exploração, a classificação e o teste de hipóteses,

f) não há controle experimental,

g) variáveis dependentes e independentes não precisam ser determinadas a priori,

h) os resultados derivados dependem do poder analítico do pesquisador,

i) mudanças de unidade de análise e de método de coleta de dados podem ocorrer durante o estudo,

j) abordam-se os "comos" e os "porquês" do fenômeno, e

k) eventos contemporâneos estão em evidência.

O Estudo de Caso, para Yin (1994, p.13), é “[...] uma investigação empírica que investiga um fenômeno atual dentro do seu contexto de vida real", e é uma opção intencional quando se acredita que as condições contextuais são altamente pertinentes ao fenômeno em estudo. Este autor afirma que fenômeno e contexto não são sempre distinguíveis em situações 
da vida real e, assim, outras características técnicas são exigidas para definir o Estudo de Caso. Explicando essas características, diz:

\begin{abstract}
A investigação do Estudo de Caso lida com as tecnicamente distintivas situações nas quais haverá muito mais variáveis de interesse do que os dados apontam, e como um resultado repousa em múltiplos recursos de evidência, com os dados precisando convergir num modelo de triangulação, e como outro resultado, beneficia-se do desenvolvimento anterior de proposições teóricas para guiar a coleta de dados e análise (YIN, 1994, p.13).
\end{abstract}

Um Estudo de Caso geralmente vale-se de evidências diversas. No presente estudo, usaram-se entrevistas individuais e observações. Yin (1994, p.85) diz sobre fontes de evidência que, sendo a maioria dos Estudos de Caso sobre temas humanos, devem ser "reportados e interpretados através dos olhos de entrevistados específicos".

Segundo Mintzberg (1979, p. 585), "Não importa quão pequena seja a nossa amostra ou qual seja o nosso interesse, busca-se entrar nas organizações com um foco bem definido para coletar tipos específicos de informação sistematicamente”.

O estudo de caso apresenta-se como uma estratégia de pesquisa que foca a dinâmica presente dentro de cenários únicos, pode envolver casos únicos ou múltiplos, e vários níveis de análise (YIN, 1994).

Essa ferramenta metodológica pode ser usada para alcançar vários objetivos: prover descrição (KIDDER, 1982), testar teoria (PINFIELD, 1986; ANDERSON, 1983), ou gerar teoria (GERSICK, 1988).

\title{
3.4 CATEGORIAS DE ANÁLISE
}

A condução da pesquisa seguiu alguns passos da pesquisadora Spink (1995) que insere suas análises num círculo contínuo composto pela teoria de representações sociais, epistemologia e metodologia, influenciando-se mutuamente, gerando um processo permanente de reflexão, e defende a análise de conteúdo como uma das formas de se ter acesso às representações.

Os seguintes passos foram utilizados para realização da pesquisa:

a) Transcrição das entrevistas.

b) Leitura flutuante do material a fim de perceber a natureza da construção e da funcionalidade das Representações Sociais. Nesta fase faz-se o mapeamento dos temas emergentes.

c) Retornar-se-á ao objetivo da pesquisa com o intuito de definir claramente o objeto da representação. Para isso inicialmente, mapeia-se o discurso a partir das 
dimensões internas da representação. E, posteriormente, mapeia-se o discurso a partir dos temas emergentes.

A categorização foi o procedimento através do qual os dados foram agrupados, segundo a parte comum existente entre eles. Para facilitar a análise, elaborou-se uma matriz com as categorias principais, nas quais as unidades temáticas criadas a partir dos dados eram classificadas ou originavam novas categorias ou subcategorias.

Após análise dos dados obtidos e formulados, procedeu-se ao confronto com aspectos teóricos que se prestaram à construção da pesquisa, procurando-se avançar para um nível superior de análise, associando-se as descobertas empíricas e teóricas com aspectos teóricos sobre as Relações de Gênero.

\section{RESULTADOS E DISCUSSÕES}

\subsection{HISTÓRICO DA ORGANIZAÇÃO HOSPITALAR}

O hospital estudado foi fundado em 14 de janeiro de 1982 por um médico, e desde então continua sendo uma empresa privada familiar. Tudo começou a partir de um sonho de levar ao paciente o atendimento de forma diferenciada, oferecendo serviços com qualidade, pontualidade, informações confiáveis e inovações constantes. Suas instalações eram modestas no início, , constituindo-se de uma casa de apenas 6 cômodos, mas com muita luta e dedicação do então fundador, cresceu e tornou-se um hospital de médio porte.

$\mathrm{Na}$ época da pesquisa (ano de 2004), os serviços prestados eram os seguintes: atendimento de consulta ao paciente, atendimento cirúrgico, avaliação e acompanhamento. $\mathrm{O}$ hospital possuía 56 leitos, e atendia em média 661 pessoas por mês, sendo que $50 \%$ dos atendimentos eram feitos pelo SUS (Sistema Único de Saúde); 30\% por meio de convênio e $20 \%$ dos atendimentos são particulares, sendo que o valor médio de faturamento mensal era de $\mathrm{R} \$ 60.000,00$.

O hospital possuía no total 71 funcionários. Na área de enfermagem, havia apenas uma enfermeira padrão, 32 auxiliares de enfermagem do sexo feminino e três auxiliares de enfermagem do sexo masculino. O conjunto de médicos era formado por nove homens e uma mulher.

Como resposta ao novo cenário competitivo em que se encontram os hospitais, a configuração gerencial da organização estudada está sendo remodelada, iniciando uma busca

Nucleus, v.6, n.2, out. 2009 
pela profissionalização, por meio do emprego de técnicas de gestão modernas e pertinentes com a organização, através da contratação de um profissional formado em administração de empresas para guiar as novas práticas administrativas que começam a fazer parte do cotidiano das organizações hospitalares.

Para fins de análise e discussão do caso, estabeleceu-se três categorias de análise para as duas classes profissionais estudadas: Médicos e Médicas, e Enfermeiros e Enfermeiras.

\subsection{MÉDICOS E MÉDICAS}

\subsubsection{A PROFISSÃO DE MÉDICO/MÉdICA E SUAS RELAÇÕES PESSOAIS E FAMILIARES}

Em função dos diferentes graus de motivação e de satisfação que o trabalho oferece para médicos e médicas e de estarem ligadas à realização pessoal e ao prazer no desempenho das atividades profissionais, os entrevistados apresentam formas diferenciadas de lidar e conciliar o lado profissional e a vida familiar.

A interdependência entre o homem e o trabalho é intermediada por valores que interferem continuamente na dinâmica estabelecida em tal relação. $\mathrm{O}$ comportamento é um mecanismo que o individuo utiliza para dar resposta a um determinado evento na busca de estabelecer seu conjunto de necessidades. O processo comportamental se inicia com a ocorrência de um advento e se conclui com a execução de uma ação, assim a resposta é a manifestação do comportamento, ou seja, muitos destes comportamentos dependem do conceito que o indivíduo tem de si, de seu grau de adaptação e ajustamento e da forma como vê seu mundo particular.

Sabe-se que a família é uma instituição calcada em uma estrutura que leva em consideração as relações de gênero, de modo que as funções entre seus componentes possuem características que são normatizadas, na maioria das veze,s em conceitos sociais.

Esses conceitos foram construídos através dos tempos em que a mulher, sendo vista como a "rainha do lar", tinha o dever de cuidar da casa e dos filhos, enquanto que o homem, como "chefe da casa", tinha o encargo de prover seu sustento. Contudo, com as mudanças que ocorreram em nossa sociedade, entre elas a entrada da mulher no mercado de trabalho, essas tarefas começaram a se misturar entre os cônjuges, e muitas vezes o que se vê é até a inversão desses papéis. Porém, na maioria dos casos, aquilo a que se vê, é a mulher que acabou por assumir, uma dupla jornada de trabalho, pois além do cuidar da casa (filhos, tarefas do lar),

Nucleus, v.6, n.2, out. 2009 
também entrou no mercado de trabalho, tendo que assumir os mesmos horários, tarefas e compromissos que seu colega do sexo masculino.

Nas entrevistas realizadas, foi representativo o fato de tanto as mulheres quanto os homens, referiram-se à dificuldade que a mulher encontra para conciliar a família e o trabalho.

Enquanto as médicas relatam uma culpa em conjugar a vida pessoal com a profissional, por sentirem-se responsáveis pelas atividades familiares e terem que se dividirem para exercer suas funções (médica e dona de casa, mãe, esposa, filha etc); os médicos por sua vez negligenciam essa dificuldade, visto que, deixam claro que quando casaram já eram médicos, o que representa que a sua vida profissional está priorizada em detrimento da pessoal, como se pode evidenciar nos discursos abaixo:

\begin{abstract}
A formação da minha vida familiar já veio depois da formação profissional, quer dizer, eu já casei depois de estar como médico, de ser médico, então[...] já foi adaptado mais nesse sentido. (Médico A)

Olha, o impacto aí, ele é forte, porque você tem que colocar a profissão sempre em primeiro lugar, então assim[...] eu tive duas filhas, eu passei muita dificuldade porque eu tinha que trabalhar os dois horários, apesar de ter flexibilidade de horário, a especialidade é muito puxada, você não tem como não atender um paciente que já te procura sempre, que é seu paciente fiel, você não tem como negar esse atendimento, [...] então é muito pesada a profissão [...] então assim muitas vezes você não pode ir numa festa da escola de seu filho porque você está envolvida num parto[...] assim é pesado, é pesado assim para conciliar a vida profissional com a vida familia[...] (Médica $\mathrm{A}$ )
\end{abstract}

Portanto, têm-se as perspectivas de um médico e de uma médica acerca do mesmo objeto: conjugar a vida pessoal com a profissional.

\title{
4.2.2 SER MÉDICA E SER MÉDICO, QUAL A DIFERENÇA?
}

A medicina não parece ser, de forma predominantemente, pensada pelos médicos como uma prática social em que tudo ganha sentido, mas sim como uma prática de sentido único. Assim, a especialização do conhecimento médico colabora para a atomização, como se nada fosse mediado pela relação entre sujeitos sociais dessa prática.

Tanto médicos como médicas não demonstram em seus discursos diferenças pelo fato de serem do sexo feminino ou masculino, contudo a escolha da especialidade parece ter uma influência em termos de diferenciação tanto em relação aos pacientes, quanto aos colegas. Por exemplo, as médicas entrevistadas acham que a especialidade de ginecologista é mais apropriada para as mulheres, enquanto os homens acham que a atividade de cirurgião é mais apropriada para os homens. A questão de ser médico ou médica não influencia a escolha da 
profissão, mas por vezes influencia a questão da escolha da especialização, geralmente onde será menos discriminado e onde terá menos retaliação.

Olha, eu acho muito importante a ginecologista ser mulher, eu me identifico muito, eu vejo que as minhas pacientes se sentem muito bem sendo examinadas por uma mulher, eu atendo muito a área de adolescência, as adolescentes elas se abrem muito mais com médica mulher[...] (Médica B)

O ginecologista homem, já durante a parte da obstetrícia, do acompanhamento de parto elas se sentem mais seguras, se sentem bem seguras de ser um homem que está atendendo[...] (Médico B)

Portanto, têm-se as perspectivas dos gêneros acerca de outro objeto: fatores que determinaram a escolha da especialidade clínica.

\subsubsection{CARACTERÍSTICAS PESSOAIS E A MEDICINA}

O desejo pela realização pessoal e profissional está ligado ao prazer que médicos e médicas expressam em relação ao que fazem. A persistência, a autoconfiança e a dedicação atingem dessa maneira um elevado poder entre suas características pessoais, pois estimulam de forma persuasiva para que estes indivíduos levem adiante seus ideais com mais eficácia.

Médicos e médicas acreditam que os resultados de suas realizações dependem de seu próprio controle e influência, esta característica está relacionada à motivação orientada para realização pessoal, o desejo de tomar responsabilidades pessoais e confiança própria. Essa motivação gera alternativas como consequência à satisfação das necessidades por meio do conhecimento e das habilidades, e principalmente quanto à forma e ao meio no qual desempenham suas atividades.

Percebe-se que as escolhas profissionais estão influenciadas pelas características pessoais que as pessoas presumem possuírem.

O gostar do que faz, para as médicas está diretamente ligado ao sucesso profissional, pois tudo que executam é feito com amor e prazer, bem como ligados aos gostos pessoais, desta maneira procuram executar suas atividades da melhor forma possível, fazendo com que tenham resultados positivos.

Em relação aos médicos, estes colocam que a facilidade de ouvir e a forma de lidar com as pessoas são requisitos para a escolha profissional.

Olha, você tem que ter ética, tem que colocar a ética acima de tudo, você tem que ter amor a profissão, você tem que gostar da profissão[...]. (Médica A) 
$\mathrm{Eu}$ acredito que a facilidade para escutar, que eu tenho, a amabilidade com os pacientes me identifica com a profissão. (Médico B)

Portanto, têm-se as perspectivas de um médico e de uma médica acerca do mesmo objeto: a forma de lidar com os pacientes.

\subsection{ENFERMEIROS E ENFERMEIRAS}

O trabalho na enfermagem corresponde a atividades desenvolvidas no espaço hospitalar, sendo formalmente realizado por uma equipe constituída pela enfermeira (profissional com nível superior), o técnico de enfermagem (formação técnica após completar o $2^{\circ}$ grau), o auxiliar de enfermagem (com curso específico após a conclusão do $1^{\circ}$ grau). $\mathrm{Na}$ informalidade e, circunstancialmente, também faz parte da equipe o atendente de enfermagem, sem formação profissional específica.

\subsubsection{A PROFISSÃO DE ENFERMEIRO/ENFERMEIRA E SUAS RELAÇÕES PESSOAIS E FAMILIARES}

A dupla ou tripla jornada de trabalho feminina significa, para as enfermeiras estudadas, uma sobrecarga e um desgaste que impõem um permanente esforço de articulação das esferas doméstica e profissional que implicam sérias repercussões.

A vida familiar e a vida no trabalho manifestam papéis de enfermeiras/mulheres/mães que não conseguem separar, nelas próprias, o mundo do lar e o do trabalho. De fato, o trabalho da enfermeira implica processos construídos não só no interior do espaço do trabalho, mas também, em processos que se desenvolvem fora desse espaço, isto é, no espaço doméstico, familiar ou social da enfermeira.

Percebe-se que as enfermeiras desse estudo evitam o sofrimento quando conseguem estar disponíveis para os dois pólos (família e trabalho) simultaneamente. Isso, entretanto, pode levar as enfermeiras a conflitos com grande carga afetiva.

Quanto aos enfermeiros, não há uma preocupação em relação a família e sua dedicação para a mesma, contudo, as preocupações são maiores quanto ao planejamento de sua vida pessoal.

Eu acho que o que as vazes prejudica a minha vida pessoal é a carga horária que é muito alta e às vezes acaba que eu deixo a família muito de lado, até meu filho que é pequeno, agora benefícios pra casa são muito poucos porque santo de casa não faz milagre, então normalmente eu entro em casa e esqueço que eu sou enfermeira, em casa eu sou mãe, eu sou mulher, eu sou uma dona de casa normal. (Enfermeira A)

Nucleus, v.6, n.2, out. 2009 
Tem esse negócio do horário 12 por 36 porque a gente não tem sábado, feriado, não pode planejar as coisas, a gente trabalha Natal, a gente tenta planejar as coisas e quando vê a gente está trabalhando. (Enfermeiro A)

Desta forma, têm-se as perspectivas dos gêneros de outra categoria profissional acerca do objeto "conjugar a vida pessoal com a profissional".

\subsubsection{SER ENFERMEIRA E SER ENFERMEIRO, QUAL A DIFERENÇA?}

A enfermagem possui uma característica marcante que a diferencia da maioria das profissões, que é o fato de ser uma profissão predominantemente exercida por mulheres. Dessa forma, isso a torna sujeita a estereótipos que marcam a vivência feminina na sociedade, onde as comunicações e os comportamentos são orientados conforme os processos de interação social que transformam simbolicamente os objetos e as pessoas representadas.

Percebe-se nos discursos dos entrevistados que esse estereotipo construído ao longo das relações entre homens e mulheres em nossa sociedade e repassado ao âmbito das organizações, ainda persiste no caso estudado.

Eu acho que, se for olhar, pra mulher a profissão é mais fácil por causa assim, que a pessoa é mais feminina, o paciente fica mais à vontade do que com enfermeiro, igual muitas senhoras que estão internadas não gostam que vá enfermeiros no quarto delas, não quer e não quer mesmo, então pra gente é uma boa. (Enfermeira A)

Olha, eu acho com sinceridade que a enfermagem, não sei se ainda , tudo bem, assim eu acho que eu ser mulher e enfermeira é bom porque pra homem eu acho que é muito, o salário da enfermagem é muito pouco, eu acho que pra um homem ser enfermeiro eu acho que ele sacrifica bastante a vida financeiramente, porque se você for olhar pro lado humanitário tudo bem é igual, porque eu acho assim pra mim esta ótimo[...] Tem diferença, porque você fala assim fulana é enfermeira aí todo mundo olha assim, mas agora você fala assim o fulano é enfermeiro então o pessoal já pensa assim que o homem que é enfermeiro, ele já leva pro lado assim, é gay, que a enfermagem é mais pra mulher[...] (Enfermeira B)

Antigamente não existia homem na enfermagem, tinha pouquíssimo, até hoje tem poucos na área por causa do preconceito, ser homem no hospital as vezes é muito explorado por a gente ser homem tem que fazer forças. (Enfermeiro A)

Desta forma, o feminino e o masculino no cuidar e no cuidado se evidenciaram nas expressões afetivas associadas ao feminino, como o carinho e a emoção; e atributos masculinos como a força e a racionalidade.

\subsubsection{CARACTERÍSTICAS PESSOAIS E A ENFERMAGEM}

As características e modos de expressão da experiência-subjetividade dos enfermeiros e enfermeiras em relação a sua profissão possibilitam organizar e analisar conhecimentos 
latentes, resultantes do modo de atuar socialmente em realidades singulares compartilhadas, assinalando aproximações ou afastamentos de definições sobre suas práticas e características pessoais.

[...] E também ter amor ao próximo, porque as pessoas entram ali e você tem que contornar, conversar. Tem que ter respeito também pelo paciente, colegas, acho que está tudo ligado. (Enfermeira C)

[...] a gente tem que fazer aquilo que gosta, e eu realmente faço aquilo que eu gosto, eu amo minha profissão, eu nunca levantei de manhã, esse período todo que eu trabalho, falando assim eu não quero ir trabalhar, eu venho porque eu gosto muito, eu amo isso aqui, eu amo a minha profissão então eu acho também assim que é uma coisa gratificante, você está fazendo uma coisa que você esta ajudando as pessoas, você vê uma pessoa que chega em estado grave e entra aqui, e ele sai bom, restabelecido, então isso pra mim é muito gratificante. (Enfermeira D)

[...] acho que a minha força de vontade; a tolerância com os problemas dos outros, tem muito para exercer a profissão. (Enfermeiro A)

Percebe-se que as enfermeiras denotam em suas falas uma importância essencial ao fato do gostar do que faz e do gostar de cuidar; ao passo que na fala dos enfermeiros pode-se extrair uma importância maior quanto ao fato de possuir características pessoais que denotam vontade de vencer.

\section{CONSIDERAÇÕES FINAIS}

As Representações Sociais permitem aos sujeitos uma orientação diante de um objeto que é socialmente relevante, constituindo-se em uma forma especial de conhecimento, compartilhado no seu grupo ou como uma categoria socialmente elaborada e dirigida à vida prática, tendo como foco a maneira pela qual os seres humanos buscam compreender as coisas que o cercam.

Portanto, estudá-las é considerar que os seres humanos pensam e não apenas manipulam informações ou agem sem explicações. A partir destas concepções, são como verdadeiras teorias do senso comum, conformadas a partir de um conjunto de conceitos e afirmações, ou seja, ciências coletivas, pelas quais se procede à interpretação e à construção das realidades sociais.

Este referencial permitiu, pois, pontuar as características e modos de expressão da experiência-subjetividade dos/das médico(as) e dos/das enfermeiros(as) e as categorias que possibilitam organizar e analisar as Representações Sociais como conhecimentos latentes, resultantes do modo de atuar socialmente em realidades singulares compartilhadas, 
assinalando aproximações ou afastamentos das práticas profissionais em organizações hospitalares.

As categorias construídas por meio do agrupamento dos dados em comum, mapeados a partir dos discursos expressos e associados aos aspectos teóricos utilizados para embasar essa pesquisa, nos permitem levantar aspectos comuns relacionados às duas categorias profissionais (Médicos/Médicas e Enfermeiros/Enfermeiras).

Investigando categorias como profissão e relações pessoais e familiares, diferença de gênero na profissão, características pessoais e profissão, pode-se observar que, apesar de uma longa jornada de lutas pela igualdade no nível de condições profissionais, as mulheres têm conquistado espaço, embora ainda resista uma representação que foi construída socialmente a respeito de seu papel.

As representações dos sujeitos sobre seu trabalho evidenciam um conjunto de significados e significações, que retratam as concepções sobre si mesmas, em determinada realidade organizacional. Essas representações convergem para um conjunto de idéias elaboradas a partir das relações estabelecidas por esses profissionais com seu espaço de trabalho, referindo-se ao nível de realização e necessidades, aos anseios, desejos, inquietações e expectativas, estando associadas às representações elaboradas e circulantes no conjunto de atividades e relações desenvolvidas no trabalho.

Constatou-se que existe uma assimetria entre as duas classes profissionais em relação ao gênero, pois enquanto na classe de Médico/Médicas as mulheres encontram uma resistência maior em termos profissionais; na classe de Enfermeiros/Enfermeiras o homem encontra mais resistência. Verifica-se, dessa forma, que a representação de profissões tipicamente masculinas ou femininas ainda persiste nas relações de trabalho, mesmo estando em igualdade de condições em termos de formação especifica, cultura e competência.

\section{REFERÊNCIAS}

ACKER, J.; VAN HOUTEN, D. R. Differential recruitment and control: the sex structuring of organizations. Administrative Science Quaterly, v. 19, n. 2. 1991.

ALVESSON, M. Gender relations and identity at work: a case study of masculinities and femininities in an advertising agency. human relations. Nova York, v. 51, n. 8, p. 969-1005, ago. de 1998.

ANDERSON, P. Decision making by objection and the Cuban missile crisis. Administrative Science Quarterly, 28. 1983.

ANDRADE, E. O. Como vejo a medicina e os médicos. Editorial. Arq Bras Oftalmol. 2004.

Nucleus, v.6, n.2, out. 2009 
ARDUINI, C.J. Temas sociais. Uberaba, 1964. p. 11.

BARDIN, L. Análise de conteúdo. Tradução de Luís Antero Reto e Augusto Pinheiro. Lisboa: Edições 70, 1979. 225 p. Título original: L’analyse de Contenu.

BENBASAT, I.; GOLDSTEIN, D.K.; MEAD, M. The case research strategy in studies of information systems. MIS Quarterly, v. 11, n. 3, 1987, pp. 369-386.

BENSCHOP, Y; DOOREWAARD, H. Covered by equality: the gender subtext of organizations. Organizations studies. Berlin, 1998.

BURREL, G.; HEARN, J. The sexuality of organization. In HEARN, J.et al. (eds) The sexuality of organization. London: Sage. 1989.

CÁLAS, B. ; SMIRCICH, L. Do ponto de vista da mulher : abordagens feministas em estudos organizacionais'. In : CLEGG, S.R. ; HARDY, C. ; NORD, W.R. (orgs.) Handbook de estudos organizacionais. São Paulo : Atlas, 1999. v. I, 465p.

CARVALHO, V. de; CASTRO, I.B.E. Reflexões sobre a prática da enfermagem. In: CONGRESSO BRASILEIRO DE ENGENHARIA, 31, Fortaleza. Anais... 1971.

CHAFETZ, J. S. Gender equality: Toward a theory of change. In R. Wallace (Ed.), Feminism and sociological theory. Newbury Park: Sage, 1989.

FRIEDSON, E. Profession of medicine. New York, Dodd Mead, 1970.

GASTALDO, D.M.; MEYER, D.E. A formação da enfermeira: ênfase na conduta em detrimento do conhecimento. Rev. Bras. Enf. Brasília, v. 42, n. 1. p. 7-13, 1989.

GERSICK, C. Time and transition in work teams. Toward a new model of group development. Academy of Management Journal, n.31, p.9-41. 1988.

GUARESCHI, P.A.; JOVCHELOVITCH, S. Introdução. In: GUARESCHI, P.A.; JOVCHELOVITCH, S. Textos em representações sociais. Petrópolis: Vozes, 1995.

HARDING, S. Introduction: Is there a feminist method? In: HARDING, S. (Ed.). Feminism and methodology. Bloomington: Indiana University Press, 1987.

HEARN, J.; PARKIN, W. Gender and organizations: a selective review and a critique of a neglected area. Organization Studies. v. 4, n. 3, 1983.

KIDDER, T. Soul of a new machine. New York: Avon, 1982.

KUHN, T. The structure of the scientific revolutions, Chicago, 1962.

LANE, S. T. M.. Psicologia social: o homem em movimento. 4 ed. São Paulo:

Brasiliense, 1986. 220p. LOURO, G.L. Gênero e magistério: identidade, história e representação [on line]. 2000. Disponível: www.ufrgs/faced/geerge/duvida.html

Nucleus, v.6, n.2, out. 2009 
LEONARD, P. Organizing Gender? looking at metaphors as frames of meaning in gender/organizational texts. gender, Work and Organization, v. 9, n. 1, jan. 2002.

LOURO, G. L. Gênero e magistério: identidade, história, representação. In: CATANI, D. B. et al. (Org.). Docência, memória e gênero: estudos sobre formação. 2. ed. São Paulo: Escrituras, 2000.

MEYER, D.E.E. [...] Por que só mulheres?: gênero da enfermagem e suas implicações. Rev. Gaúcha de Enf. Porto Alegre, v. 14, n. 1, p. 45-52. jan. 1993.

MINAYO, M.C.S. O desafio do conhecimento. São Paulo: HUCITEC/ABRASCO, 1996.

MOSCOVICI, S. La psichanalyse, son image et son public. Paris: Universitaries de France, 1976.

MILLS, A. J.; TANCRED, P. (eds) Introduction. Gendering Organizational Analysis. Newbury Park: Sage. 1992.

MINTZBERG, H. An emerging strategy of "direct" research. Administrative Science Quarterly, n.30, p.160-197. 1979.

NICHOLSON, L. J. (Ed.). Feminism/Postmodernism. Nova York: Routledge, 1990.

PINFIELD, L. A field evaluation of perspectives on organizational decision making. Administrative Science Quarterly, n.31, p.365-388. 1986.

RAMOS, R. A integração sanitária: doutrina e prática. 1972. Tese (Livre Docência). Faculdade de Saúde Pública/Universidade de São Paulo.

SÁ, C. P. A construção do objeto de pesquisa em representações sociais. Rio de Janeiro: UERJ, 1998.

SABAT, R. Quando a publicidade ensina sobre gênero e sexualidade. Petrópolis: Vozes, 1999.

SALLES, P. História da medicina no Brasil. Belo Horizonte: Gr. Holman, 1971.

SCOTT, J. W. Gênero: uma categoria útil para análise histórica. Educação \& Realidade. Porto Alegre, v. 20, n.2. jul/dez, 1995.

SILVA, G. B. da. Enfermagem profissional: análise crítica. São Paulo: Cortez, 1986. 143p.

SILVA, L. H. Representações sociais e educação: refletindo sobre as possibilidades de um diálogo. Revista Psicologia em Estudo, Universidade Estadual de Maringá, v. 3, n.1, p. 105124, jan/julho 1998.

SPINK, M. J. Desvendando as teorias implícitas: uma metodologia de análise das Representações Sociais. In: GUARESCHI, P.A.; JOVCHELOVITCH, S. Textos em representações sociais. 2. ed. Petrópolis: Vozes, 1995. p.117-145. 
UCHINAKA F. Mulher: mercado de trabalho é marcado por desigualdades. Combate ao Racismo: Documentos, São Paulo, 2004. Disponível e http://www.pt.org.br/site/secretarias_def/secretarias_int.asp?cod=2665\&cod_sis=4\&cat=57 Acesso em 20 mar. 2005.

YIN, R. K. Case study research: design and methods. 2nd ed. USA: Sage Publications Inc, 1994. 